\title{
WPLYW PANDEMII KORONAWIRUSA SARS-COV-2 NA CZĘSTOŚĆ WYSTĘPOWANIA I NASILENIE BÓLÓW KRĘGOSEUPA LĘDŹWIOWEGO W GRUPIE PRACOWNIKÓW BIUROWYCH PRZENIESIONYCH DO PRACY ZDALNEJ
}

The impact of the SARS-Cov-2 coronavirus pandemic on low back pain in the group of office workers shifted to home office.

\section{Słowa kluczowe:}

praca zdalna, kręgosłup, bóle

kręgosłupa, koronawirus,

pandemia.

\section{Key words:}

remote work, home office, spine, low back pain (LBP), coronavirus, pandemic.

\section{Streszczenie}

Wstęp.

Bóle dolnego odcinka kręgosłupa są jednym z głównych powodów nieobecności w pracy. Społeczne dystansowanie, praca zdalna i ograniczenie aktywności fizycznej moga prowadzić do jeszcze dłuższego czasu spędzanego w pozycji siedzacej.

\section{Cel pracy.}

Analiza wpływu sytuacji pandemii na bóle kręgosłupa lędźwiowego oraz znajomości rozwiązań profilaktycznych wśród pracowników biurowych pracujących zdalnie.

Badana grupa i metoda badań.

Badanie przeprowadzono przy pomocy internetowego sondażu diagnostycznego na grupie 143 pracowników administracyjno-biurowych w wieku 21-49 lat, którzy przeszli na zdalny tryb pracy $\mathrm{z}$ powodu pandemii koronawirusa.

Wyniki.

Przejście na tryb zdalny pracy w związku z pandemią COVID-19 ma wpływ na większą częstość występowania i nasilenie odczuwania bólu kręgosłupa części lędźwiowej.

Wnioski.

Należy zwiększyć działania w zakresie profilaktyki i terapii bólów kręgosłupa lędźwiowego wśród osób pracujących zdalnie.

\section{Summary}

Background.

Low back pain is one of the main reasons for being absent at work. Social distancing, working remotely, and limiting physical activity can lead to prolonged sitting time.

Aim.

Analysis of the impact of a pandemic situation on low back pain and knowledge of preventive solutions among office workers working remotely.

Material and method.

The study was conducted using an online diagnostic survey on | a group of 143 administrative and office workers aged 21-49 who switched to remote work due to the coronavirus pandemic.

Results.

Switching to remote work mode in 
connection with the COVID-19 pandemic has an impact on the higher incidence and intensity of pain in the lumbar spine.

\section{Conclusions.}

Activities in the field of prevention and treatment of low back pain among people working remotely should be increased.

\section{Wstęp}

W grudniu 2019 roku udokumentowano pierwsze przypadki nowej choroby koronawirusowej (COVID-19). Trzy miesiace później Światowa Organizacja Zdrowia (WHO) ogłosiła pandemię COVID-19 [1]. We wrześniu 2020 roku potwierdzonych przypadków na świecie było blisko 27 milionów. Strategie niefarmakologiczne okazały się być najbardziej skutecznym mechanizmem w redukcji rozprzestrzeniania się choroby wirusowej. Sa to społeczne dystansowanie, używanie maseczek i kwarantanny. Społeczne dystansowanie celuje w redukcji interakcji międzyludzkich, aby zapobiec zarówno zbyt szybkiemu rozprzestrzenianiu się patogenu, jaki i liczby zakażeń, co przekłada się na zabezpieczenie systemu zdrowia przed zapaścią. Strategię realizowano także poprzez ograniczenie wszystkich absolutnie niekoniecznych do życia aktywności i usług, m.in. siłowni, zajęć i wydarzeń sportowych, czy koncertów $[2,3,4,5,6]$. Mimo, że społeczne dystansowanie jest najlepszą strategią $\mathrm{w}$ redukcji nowych zachorowań na COVID-19, to może mieć swoje konsekwencje jako zdrowotnie powiązane skutki uboczne, takie jak: ból mięśniowo-szkieletowy, fizyczna nieaktywność, kiepskie zdrowie psychiczne, czy ekonomiczne wyzwania, zarówno indywidualne jak i społeczne [7]. Ból dolnego odcinka kręgosłupa dotyka 7,3\% światowej populacji i jest jednym z głównych powodów inwalidztwa oraz nieobecności w pracy $[8$, 9]. Społeczne dystansowanie może prowadzić do jeszcze dłuższego czasu spędzanego w pozycji siedzącej [10], co jest powiązane ze zwiększonym narażeniem na bóle dolnego odcinka kręgosłupa [11,12]. Ponadto aktywność fizyczna wykazuje dobroczynne efekty na ból dolnego odcinka kręgosłupa i inne schorzenia mięśniowoszkieletowe, co uwydatnia jak ważne jest promowanie bycia aktywnym fizycznie [13] To ograniczenie wymusza potrzeby promowania aktywności fizycznej, szczególnie podczas dystansowania społecznego, aby zmniejszyć czas spędzany sedenteryjnie oraz ryzyko wystąpienia i nasilenia bólu dolnego odcinka kręgosłupa [14].

\section{Cel pracy}

Celem pracy jest ocena częstości występowania i nasilenia bólów dolnego odcinka kręgosłupa na skutek pandemii COVID-19 i przejścia na tryb pracy zdalnej. Ponadto zweryfikowano wiedze pracowników administracyjno-biurowych pracujących zdalnie na temat działań terapeutycznych oraz sposobów autoterapii.

\section{Badana grupa}

Badanie przeprowadzono na grupie liczacej 143 osoby (106 kobiet i 37 mężczyzn) w wieku 21-49 lat (średnia wieku 31 lat) o stażu pracy od 1 do 25 lat (średni staż pracy 7,5 roku). Warunkiem przystąpienia do badania było wykonywanie pracy biurowej przed pandemią oraz przejście na tryb pracy zdalnej w jej trakcie. Kryterium wykluczające stanowiło wykonywanie pracy w warunkach zdalnych poniżej 3 miesięcy oraz staż pracy biurowej poniżej 1 roku.

\section{Metoda badań}

Badanie zostało wykonane przy pomocy internetowego sondażu statystycznego - ankiety Google docs. Ankieta składała się z 16 pytań, podzielonych na sekcje:

- Metryczka - (płeć, wiek, wzrost, waga, staż pracy)
- Styl życia i poziom aktywności fizycznej

- Dolegliwości kręgosłupa lędźwiowego przed i w trakcie pandemii

- Kwestionariusz bólu krzyża

- Sposoby radzenia sobie z bólem.

Do opracowania wyników użyto arkusz kalkulacyjny Google.

\section{Dyskusja}

Pandemia COVID-19 wpływa na wiele aspektów naszego życia. Niemalże z dnia na dzień wprowadzono liczne obostrzenia związane ze społecznym dystansowaniem, zostawaniem w domu dla bezpieczeństwa swego i innych. $\mathrm{Z}$ tego powodu należy zwrócić uwagę na zachowanie odpowiedniego poziomu aktywności fizycznej Polaków.

Według badań przeprowadzonych w czerwcu bieżącego roku na próbie 1000 losowych ankietowanych wykazano, że około $43 \%$ Polaków ograniczyło swoją aktywność fizyczną w związku z pandemią $[15,16]$. W opublikowanych wynikach badań własnych, ograniczenie aktywności fizycznej w czasie pandemii zaobserwowano aż u 69\% ankietowanych osób pracujących zdalnie [17]. W badaniach tych stwierdzono także, że tylko $43 \%$ respondentów spełnia rekomendacje WHO w zakresie aktywności fizycznej, co jest i tak znacznie powyżej polskiej średniej według Eurostat [18].

Zdrowie fizyczne połączone $\mathrm{z}$ niską aktywnością fizyczną, pracą zdalną oraz zwiększonymi zachowaniami sedenteryjnymi, sprzyja występowaniu chorób mięśniowo-szkieletowych, a w szczególności bólom dolnego odcinka kręgosłupa. Według badań Malińskiej i wsp. (2014) odsetek pracowników pracujących przy komputerze cierpiących z powodu bólów w rejonie lędźwiowokrzyżowym kręgosłupa wynosi 38\% [19]. 


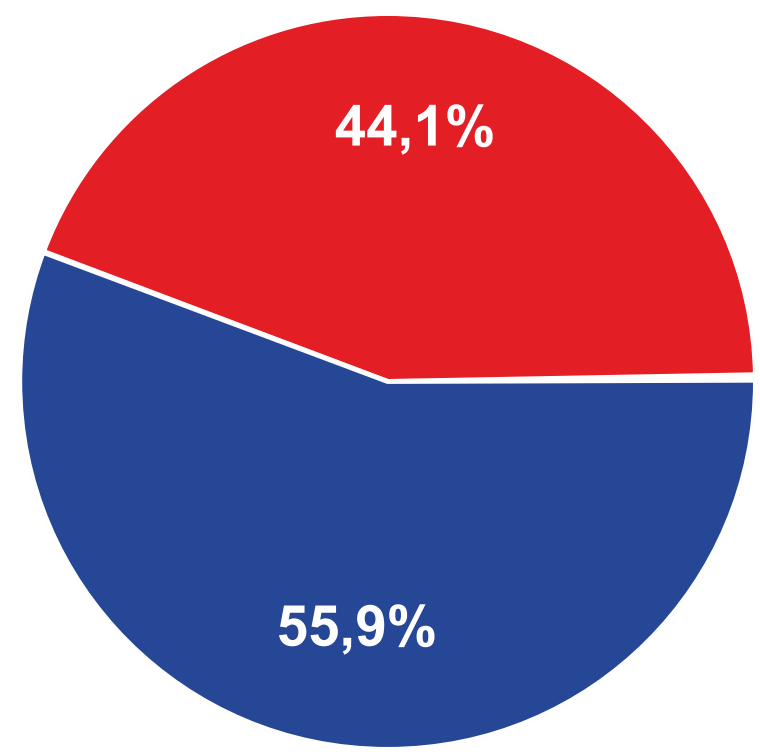

Tak

Nie

Ryc. 1. Procentowy rozkład wzrostu częstotliwości odczuwania dolegliwości bólowych dolnego odcinka kręgosłupa podczas pandemii COVID19 u badanych $(n=143)$ [źródło własne]

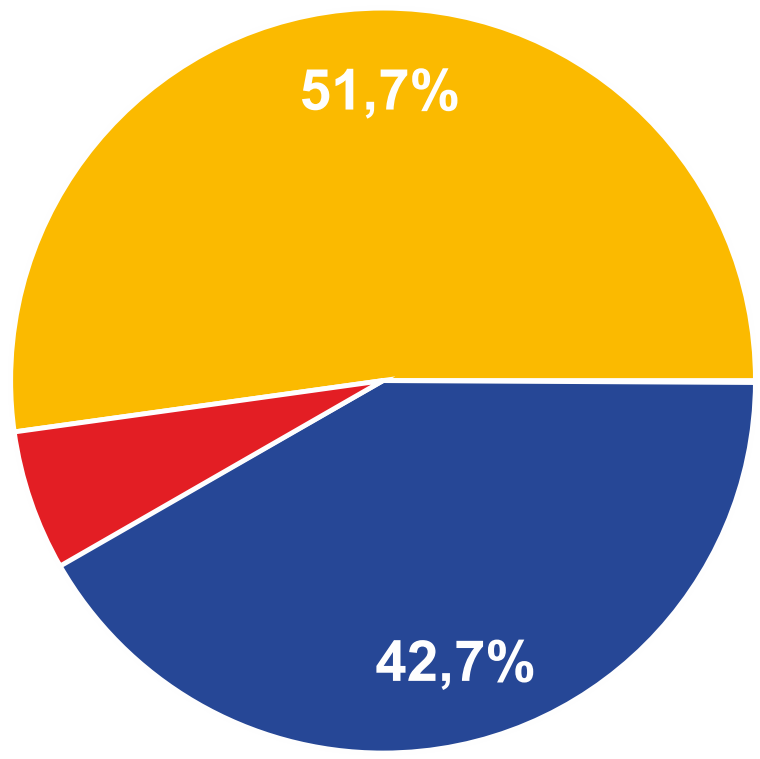

Boli bardziej

Boli mniej

Bez zmian

Ryc. 2. Procentowy rozkład zmian nasilenia dolegliwości bólowych ze strony dolnego odcinka kręgosłupa u respondentów (n=143) [źródło własne]

Badanie własne wskazuje na znacznie częstsze występowanie tej dolegliwości, której częstość wyniosła aż 74,8\%. Przytoczone badanie Malińskiej było przeprowadzone w 2014 roku, więc wzrost częstości występowania bólów w okolicy dolnego odcinka kręgosłupa może wskazywać na niekorzystny trend związany z coraz częstszą i dłuższą pracą siedzącac. Może mieć to związek z ograniczeniem aktywności fizycznej i zwiększeniem sedenteryjnych zachowań - także z powodu pandemii COVID-19.

Sobolewska i wsp. [20] wykazali, że styl życia wyrażony aktywnością fizyczną wpływa na częstość występowania bolesności ze strony kręgosłupa oraz ma wpływ na samo wystapienie objawów bólowych. Badanie własne wykazało z kolei, że aktywność fizyczna obniżyła się aż u 69,2\% ankietowanych 


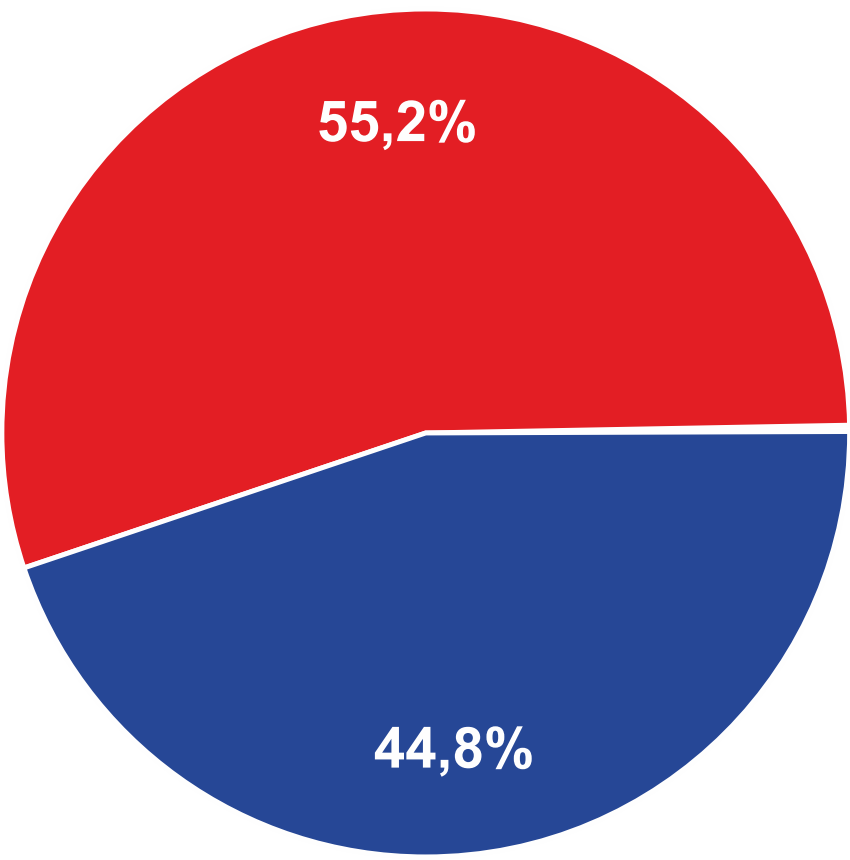

\section{Tak \\ Nie}

Ryc. 3. Rozkład procentowy korzystania w przeszłości z usług fizjoterapeuty w ramach przeciwdziałania dolegliwościom bólowym ze strony dolnego odcinka kręgosłupa ( $n=143)$ [źródło własne]

respondentów, a czas spędzany dziennie w pozycji siedzacej w przedziale od 8 do 12 godzin zaznaczyło aż $51,7 \%$ badanych, a 5,6\% badanych zadeklarowało, że w pozycji siedzącej spędza ponad 12 godzin dzienne. Warto zauważyć, że aż 55,9\% badanych sygnalizuje zwiększenie częstotliwości występowania bólu dolnego odcinka kręgosłupa w trakcie pandemii COVID-19, a 42,7\% wskazuje na nasilenie się $\mathrm{w}$ tym okresie objawów bólowych kręgosłupa. Na brak nasilenia się bólu wskazuje $51,7 \%$ badanych, ale tylko 5,6\% na zmniejszenie dolegliwości. Taki trend może wskazywać na szkodliwość pracy zdalnej u pracowników biurowych wykonujących pracę zdalną.

Z badań Kantar [21], które zostało zlecone przez Krajową Izbę Fizjoterapeutów (KIF) wynika, że niespełna 5\% społeczeństwa nie wie nic o fizjoterapii, zaś 50\% Polaków nigdy nie skorzystało z usług fizjoterapeutycznych. Wyniki te pokrywają się z wynikami badań własnych, gdzie 55,2\% respondentów nie skorzystało mimo bólów kręgosłupa z usług fizjoterapeutycznych.
Według badań Derewieckiego i wsp. [22] w chwili wystapienia bólu 13,7\% nie stosowało żadnej autoterapii, co jest wynikiem zbliżonym, ale trochę niższym niż w badaniu własnym 18,9\%. Może mieć to związek z tym, że na to pytanie odpowiadały również osoby bez problemów bólowych ze strony dolnego odcinka kręgosłupa. Zauważyć należy również, że we wspomnianym badaniu ankietowani najczęściej wskazywali stosowanie leków przeciwbólowych (37,6\%), żeli i maści przeciwbólowych $(36,9 \%)$, przyjmowanie pozycji lezącej $(35,9 \%)$, ciepłolecznictwo $(12,5 \%)$. Co ciekawe, ćwiczenia i gimnastykę jako metody leczenia bólu pleców próbowało jedynie $5,8 \%$ badanych.

W badaniu własnym stwierdzono o wiele wyższe wartości procentowe dla poszczególnych aktywnych form autoterapii: rozciąganie $(54,5 \%$,$) zajęcia$ fitness/pilates/joga $(44,1 \%)$, rolowanie $(25,2 \%)$ oraz stosowanie środków farmakologicznych $(29,4 \%)$ i ciepłolecznictwo $(20,3 \%)$.
Obecnie dolegliwości bólowe kreggosłupa lędźwiowego stanowią poważny problem ekonomiczny i społeczny. Poprzez rozwój cyberprzestrzeni oraz zwiększenia możliwości związanych z nowymi technologiami oraz możliwości pracy zdalnej przy komputerze, znacznie wzrasta czas spędzany w pozycji siedzacej. Przejawia się to m.in. poprzez różne formy pracy wykonywanej siedzac, bierny odpoczynek przed telewizorem, laptopem, tabletem czy telefonem.

Postęp cywilizacyjny widzimy też w transporcie. Na co dzień przemieszczamy się pasywnymi środkami transportu np. samochód, autobus, czy elektryczna hulajnoga. Ponadto obecna sytuacja pandemiczna jeszcze bardziej sprzyja ograniczaniu aktywności fizycznej. W wyniku izolacji/zamknięcia siłowni, aktywność fizyczna wielu osób została drastycznie ograniczona. W miare rozprzestrzeniania się pandemii istnieje duże ryzyko dalszego ograniczenia aktywności fizycznej i w konsekwencji pogorszenia się stanu zdrowia całego 
$60,00 \%$

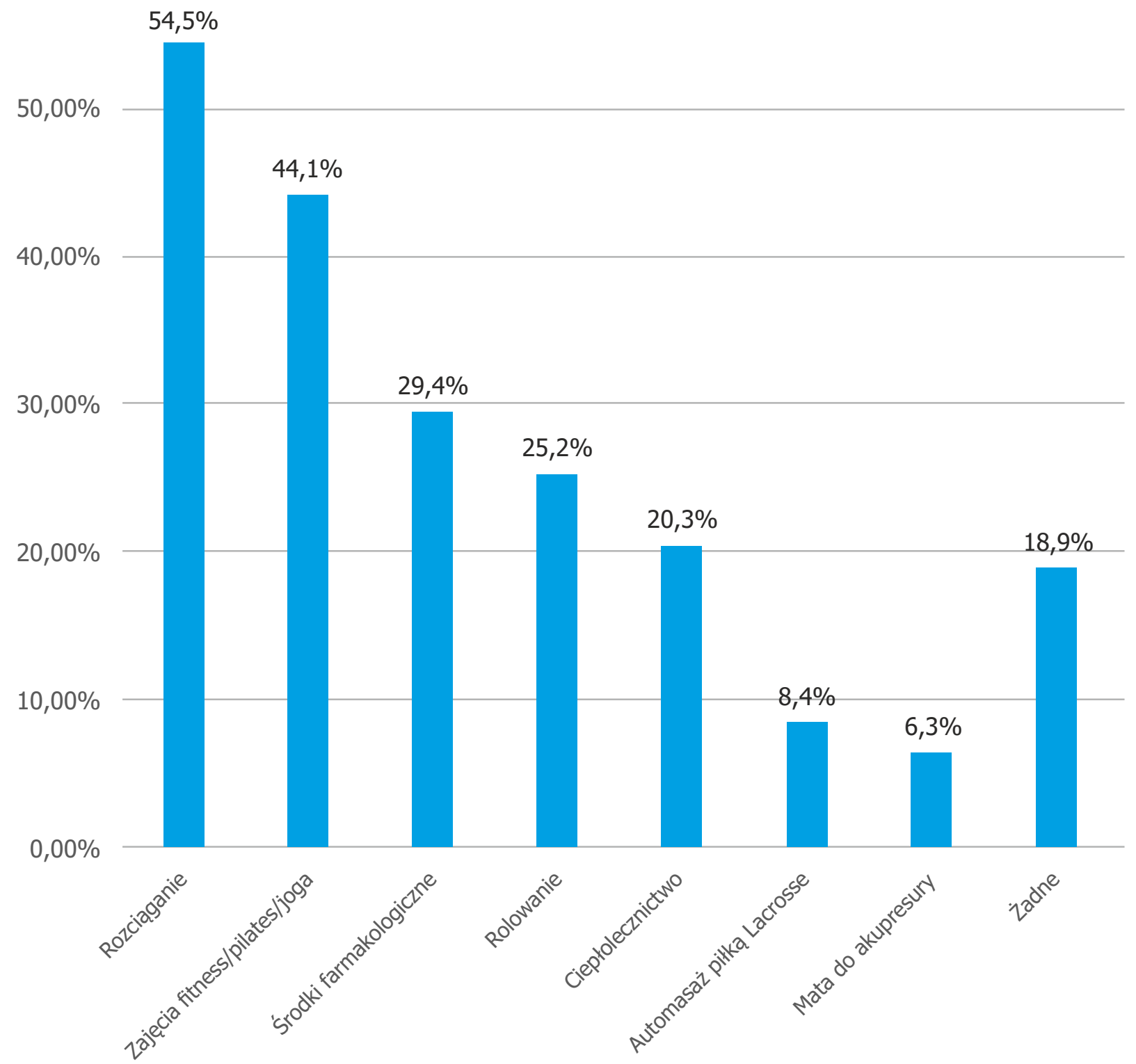

Ryc.4. Sposoby autoterapii, z których korzystają badani respondenci w ramach profilaktyki i terapii bólu dolnego odcinka kręgosłupa (n=143) [źródło własne].

społeczeństwa jako skutek uboczny pandemii wirusa SARS-COV-2. Znając te zagrożenia nie powinniśmy na to pozwolić i już teraz należałoby intensyfikować wszelkie działania i możliwości profilaktyczne takie jak uświadamianie i edukacja o istnieniu problemu, o możliwościach i skuteczności profilaktyki i fizjoterapii oraz rozmaitych strategiach samodzielnego radzenia sobie $\mathrm{z}$ problemami bólowymi kręgosłupa.

\section{Wnioski}

1. Przejście na tryb zdalny pracy w związku z pandemią COVID-19 ma wpływ na większą częstość występowania i nasilenie odczuwania bólu kręgosłupa części lędźwiowej.

2. Pracownicy biurowi pracujący zdalnie są poinformowani odnośnie możliwości autoterapii oraz stosunkowo często korzystają z usług fizjoterapeuty.

\section{Bibliografia}

1. World Health Organization. Coronavirus disease 2019 (COVID-19) situation report-51. Geneva, Switzerland. World Health Organization (WHO) 2020.

2. Dong E., Du H., Gardner L. An interactive web-based dashboard to track COVID19 in real time. Lancet Infect Dis. 2020,20:533-4. 
3. Arshad Ali S., Baloch M., Ahmed N. et al. The outbreak of Coronavirus Disease 2019 (COVID-19)-An emerging global health threat.; J Infect Public Health. 2020;13:644-6.

4. Sohrabi C., Alsafi Z., O'Neill N., et al. World Health Organization declares global emergency: A review of the 2019 novel coronavirus (COVID-19). International Journal of Surgery 2020;76:71-6.

5. Nussbaumer-Streit B., Mayr V., Dobrescu Al., et al. Quarantine alone or in combination with other public health measures to control COVID-19: a rapid review. Cochrane Database Syst Rev. 2020 Apr 8;4(4):CD013574. doi:10.1002/ 14651858.CD013574.

6. Wilder-Smith A., Freedman D.0. Isolation, quarantine, social distancing and community containment: pivotal role for old-style public health measures in the novel coronavirus (2019-nCoV) outbreak. J Travel Med 2020 Mar 13;27(2):taaa020. doi: 10.1093/jtm/ taaa020.

7. Paules C.I., Marston H.D., Fauci A.S. Coronavirus Infections-More Than Just the Common Cold. JAMA - Journal of the American Medical Association. 2020;323:707-8.

8. Vos T., Allen C., Arora M., et al. Global, regional, and national incidence, prevalence, and years lived with disability for 310 diseases and injuries, 1990-2015: a systematic analysis for the
Global Burden of Disease Study 2015. Lancet 2016;388:1545-602.

9. Hartvigsen J., Hancock M.J., Kongsted A. et al. What low back pain is and why we need to pay attention. The Lancet 2018;391:2356-67.

10. Chen P., Mao L., Nassis G.P. et al. Coronavirus disease (COVID-19): The need to maintain regular physical activity while taking precautions. J Sport Health Sci 2020; 9 (2):103-4.

11. Hussain S.M., Urquhart D.M., Wang Y. et al. Associations between television viewing and physical activity and low back pain; Medicine (Baltimore). 2016 Jun; 95(25): e3963.

12. Amorim A.B., Levy G.M., PerezRiquelme $F$. et al. Does sedentary behavior increase the risk of low back pain? A population-based cotwin study of Spanish twins. Spine J. 2017;17:93342.

13. Pinto R.Z., Ferreira P.H., Kongsted A. et al. Self-reported moderate-to-vigorous leisure time physical activity predicts less pain and disability over 12 months in chronic and persistent low back pain.; Eur J Pain. 2014;18:1190-8.

14. Shiri R, Falah-Hassani K. Does leisure time physical activity protect against low back pain? Systematic review and metaanalysis of 36 prospective cohort studies. British Journal of Sports Medicine. 2017;51:1410-8.
15. https://www.who.int/news-room/factsheets/detail/physical-activity ; (dostęp: 10.09.2020 r.)

16. https://ec.europa.eu/jrc/en/health-knowledgegateway/promotion-prevention/physicalactivity; (dostęp:10.09.2020 r.)

17. Wroński Z., Kanarek M., Oleksiak J., Kużdżał A. Wpływ pandemii koronawirusa SARS-Cov-2 na ograniczenie aktywności fizycznej w grupie pracowników biurowych przeniesionych do pracy zdalnej. Physiotherapy Review 2020,3:37-42.

18. Time spent on health-enhancing (nonwork-related) aerobic physical activity by sex, age and educational attainment level. Źródło:https://ec.europa.eu/ eurostat/ web/products-eurostat-news/-/DDN20170302-1(dostęp: 10.09.2020 r.).

19. Malińska M. Profilaktyka dolegliwości mięśniowo-szkieletowych związanych z wykonywaną pracą - promocja aktywności fizycznej w miejscu pracy. Bezp. Pr. - Nauka Prakt.2014 (3):25-29.

20. Sobolewska P., Szyjka A., Szczepanowska B. Dolegliwości bólowe kręgosłupa w grupie pracowników biurowych; Ostry dyżur 2016,9,3:69-72.

21. https://www.politykazdrowotna.com/ 50795, ilu-polakow-korzysta-z-uslugFizjoterapeuty (dostęp:10.09.2020 r.).

22. Derewiecki T. i wsp. Znajomość zasad profilaktyki dolegliwości bólowych kręgosłupa wśród mieszkańców powiatu zamojskiego. Hygeia Public Health 2012, 47(3):365-370. 